Received: 10 August 2017

Accepted: 27 November 2017

Published online: 21 December 2017

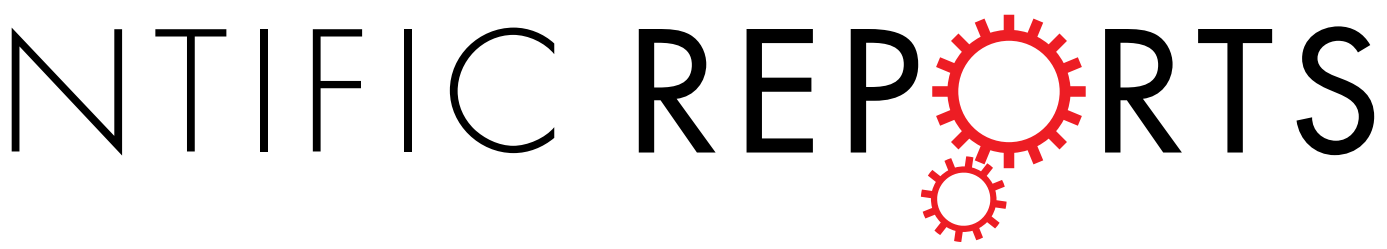

\title{
OPEN Towards sustainable processing of columbite group minerals: elucidating the relation between dielectric properties and physico- chemical transformations in the mineral phase
}

\author{
Sergio Sanchez-Segado $\mathbb{D}^{1}$, Tamara Monti ${ }^{2}$, Juliano Katrib $\mathbb{1}^{2}$, Samuel Kingman ${ }^{2}$, \\ Chris Dodds $\mathbb{D}^{2}$ \& Animesh Jha ${ }^{1}$
}

Current methodologies for the extraction of tantalum and niobium pose a serious threat to human beings and the environment due to the use of hydrofluoric acid (HF). Niobium and tantalum metal powders and pentoxides are widely used for energy efficient devices and components. However, the current processing methods for niobium and tantalum metals and oxides are energy inefficient. This dichotomy between materials use for energy applications and their inefficient processing is the main motivation for exploring a new methodology for the extraction of these two oxides, investigating the microwave absorption properties of the reaction products formed during the alkali roasting of niobium-tantalum bearing minerals with sodium bicarbonate. The experimental findings from dielectric measurement at elevated temperatures demonstrate an exponential increase in the values of the dielectric properties as a result of the formation of $\mathrm{NaNbO}_{3}-\mathrm{NaTaO}_{3}$ solid solutions at temperatures above $700^{\circ} \mathrm{C}$. The investigation of the evolution of the dielectric properties during the roasting reaction is a key feature in underpinning the mechanism for designing a new microwave assisted hightemperature process for the selective separation of niobium and tantalum oxides from the remainder mineral crystalline lattice.

Niobium $(\mathrm{Nb})$ and tantalum (Ta) are considered strategic materials due to their importance in high technology applications. These two elements are significant constituents for the manufacturing of super-alloys for the aerospace industry, high-strength low-alloy steel (HSLA) for construction, low temperature superconductor (LTS) wires for medical equipment (i.e. MRI and NMR), particle accelerators and nuclear fusion equipment. The oxides of niobium and tantalum are also used for manufacturing capacitors, soft-ferroelectric materials, and in the engineering of advanced bone implant materials ${ }^{1,2}$. Such applications in high-value product manufacturing have pushed the demand for these two materials, estimated at an annual increase rate of $4.7 \%$ for tantalum and $10 \%$ for niobium ${ }^{1,2}$. As a consequence, there is an encouraging trend for their recovery from scrap materials and low grade minerals.

Columbite group minerals (CGM) are the main source for the production of niobium and tantalum metals. The industrial treatment of CGM concentrates consists of the digestion of the concentrate using a mixture of sulphuric and hydrofluoric acid at temperatures between 250 and $300^{\circ} \mathrm{C}$ to form niobium and tantalum fluorides, which are selectively separated by solvent extraction (SX) using an organic medium. The main drawbacks of the current technology are ${ }^{3-5}$ :

${ }^{1}$ School of Chemical and Process Engineering, University of Leeds, Leeds, LS2 9JT, UK. ${ }^{2}$ Microwave Process Engineering Research Group. Dept. of Chemical and Environmental Engineering, The University of Nottingham, Nottingham, NG7 2RD, UK. Correspondence and requests for materials should be addressed to S.S.-S. (email: S. SanchezSegado@leeds.ac.uk) 
- The leaching process is not selective and large amounts of impurities are co-dissolved with niobium and tantalum leading to huge costs associated with the regeneration and loss of fluorine.

- The organic extractants used in the SX processes are not optimized.

- The use of HF and organic solvents leads to potentially dangerous operations and serious environmental pollution.

- The process generates a substantial solid and liquid waste, which are difficult to dispose of because of their chemical reactivity.

In 1990 the production of 1 ton of niobium and tantalum oxides generated an average of 14 tons of solid waste of which $500 \mathrm{~kg}$ were radioactive $e^{6}$.The reduction of solid and liquid waste is still a major concern for the industry $y^{5,6}$. Current research has also focused on the reduction of the HF used and its replacement with gaseous mixtures based on chlorine gas $^{7-12}$. However, the improvements achieved on a laboratory scale do not meet the sustainability criteria established in The World Summit on Sustainable Development held in Johannesburg on $2002^{13}$, which is why the industry sector continues to explore a sustainable approach for both utilizing mineral reserves and recycling. Recently, we reported ${ }^{14-17}$ the importance of alkali roasting and selective leaching technique with sodium or potassium salts as an alternative for the treatment of industrial minerals and wastes, namely ilmenite, bauxite and red mud, and critical metals tantalum, niobium and rare-earth metal oxide minerals.

\section{Dielectric heating of minerals}

Recent studies from the Microwave Process Engineering group at the University of Nottingham demonstrate the economic viability of microwave heating at industrial scale for the beneficiation of copper minerlas ${ }^{18,19}$. Based on the results of mineral sorting trials, a crucial parameter that quantifies the storage of electromagnetic energy and the thermal conversion is the complex dielectric permittivity of the material as a function of the frequency, described by equation (1):

$$
\varepsilon=\varepsilon^{\prime}-j \varepsilon^{\prime \prime}=\varepsilon_{o} \varepsilon_{r}^{\prime}-j \varepsilon_{o} \varepsilon^{\prime \prime}{ }_{r}
$$

where $\varepsilon_{0}$ is the dielectric permittivity of the vacuum, $\varepsilon^{\prime}$ and $\varepsilon^{\prime \prime}$ are the real and imaginary parts of the complex dielectric permittivity, respectively, and $\varepsilon_{\mathrm{r}}^{\prime}$ and $\varepsilon^{\prime \prime}{ }_{\mathrm{r}}$ are the real and imaginary part of the relative complex dielectric permittivity, respectively. The real part quantifies the storage of electromagnetic energy, whereas the thermal conversion is proportional to the imaginary part of the complex permittivity, also known as the loss factor ${ }^{20}$. During microwave heating, mineral constituents with higher values of $\varepsilon^{\prime \prime}$ are selectively heated in comparison to the constituents with relatively lower loss factor values. However, differences in chemical composition, formation of reaction products and processing temperatures affect the dielectric properties which is why there is a need to understand the interaction of the CGM with microwave energy before considering microwave heating as an enabling tool for this process $^{21}$.

In the context of engineering a novel technique for the extraction of niobium-tantalum oxides from columbite-tantalite minerals, we have reviewed the importance of dielectric properties of these two oxides for microwave processing, and on this basis we propose a combination of alkali roasting using microwave heating source as a first step in the conservation of energy and approaches for waste minimization. By characterising the dielectric properties in the microwave region, in future we will be able to make comparisons with the resistive and gas-fired heating methods. Also, the combination of microwave heating with alkali roasting will offer us an opportunity to design leaching process by minimizing the generation of hazardous waste.

\section{Methods}

The columbite concentrate from the Democratic Republic of Congo supplied by the Tantalum-Niobium International Study Centre was characterized using X-Ray powder diffraction (XRPD) with Cu-Ko radiation over an angle (2 $\theta$ ) range of 7 to $80^{\circ}$, X-Ray fluorescence (XRF) and scanning electron microscopy with energy dispersive X-ray analysis capabilities (SEM/EDX). Results are presented in the supplementary information Tables S1, S2 and Figure S1. The XRPD pattern in Fig. 1 shows that the major phases present in the mineral are ferro-columbite $\left(n^{\circ} 1\right)$ and tapiolite $\left(n^{\circ} 3\right)$, whereas muscovite $\left(n^{\circ} 5\right)$, nacrite $\left(n^{\circ} 4\right)$ and free silica $\left(n^{\circ} 2\right)$ are identified as minor phases.

The dielectric properties of the columbite concentrate and its mixture 1:1 with sodium bicarbonate were characterized using the cavity perturbation method ${ }^{22}$ from room temperature to $1000^{\circ} \mathrm{C}$ with increments of $100^{\circ} \mathrm{C}$ between measurements. The powders were thoroughly mixed using mortar and pestle and held at each temperature for 10 minutes to allow the temperature to stabilise. The dielectric values were measured, using a vector network analyser (VNA) at a fixed frequency $(2470 \mathrm{MHz})$, close to the allocated microwave heating frequency of $2450 \mathrm{MHz}$. Due to the short reaction times, a 1:1 ratio which corresponds to 1.5 times the stoichiometric amount of sodium bicarbonate, was employed to enhance the formation of the reaction products at lower temperatures. In order to relate the variation of the dielectric properties with the phase transformations occurring at each temperature, a direct comparison between the dielectric parameters and the thermo-gravimetric analysis (TGA) from room temperature to $1000^{\circ} \mathrm{C}$ at a heating rate of $5^{\circ} \mathrm{C} / \mathrm{min}$ was also carried out. These experiments were complemented with isothermal roasting tests of the mixtures in air from $100^{\circ}$ to $1000^{\circ} \mathrm{C}$ with incremental steps of $100^{\circ} \mathrm{C}$ in a CARBOLITE $\mathrm{MoSi}_{2}$ resistance furnace using recrystallized alumina crucibles. For isothermal tests, each sample was held at the target temperature for 15 minutes and then quenched in air for further examination using XRPD (Bruker D8 with X'Pert High Score plus software) and SEM/EDX (Carl Zeiss EVO MA15).

Data availability. All data generated or analysed during this study are included in this article. 


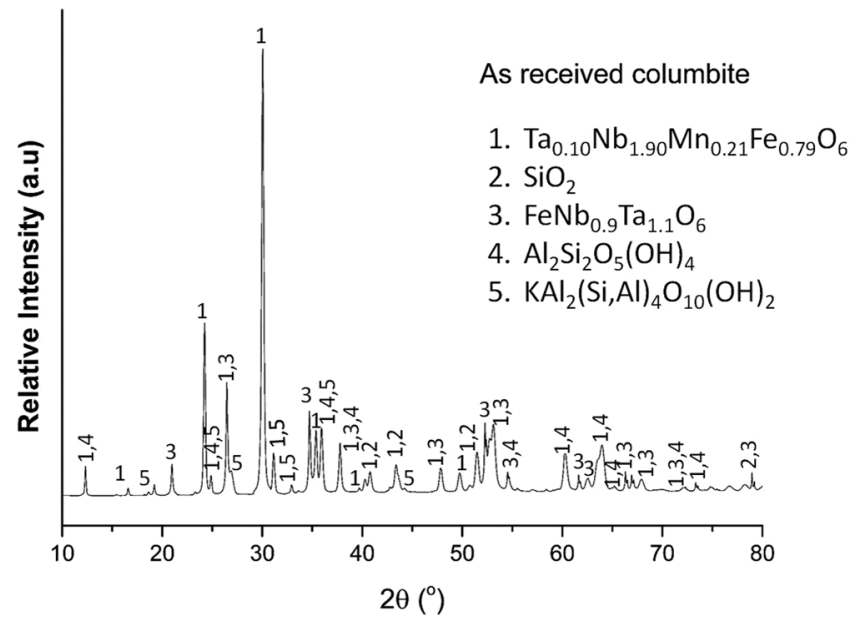

Figure 1. XRPD pattern of the as received columbite. The diffraction data compares well with ICDD refs. 04-01 $2 \mathrm{Ta}_{0.1} \mathrm{Nb}_{1.90} \mathrm{Mn}_{0.21} \mathrm{Fe}_{0.79} \mathrm{O}_{6}, 01-077-8310 \mathrm{SiO}_{2}, 04-006-1584 \mathrm{Ta}_{1.1} \mathrm{Nb}_{0.9} \mathrm{FeO}_{6}, 00-029-1488 \mathrm{Al}_{2} \mathrm{Si}_{2} \mathrm{O}_{5}(\mathrm{OH})_{4}, 00-058-$ $2035 \mathrm{KAl}_{2}(\mathrm{Si}, \mathrm{Al})_{4} \mathrm{O}_{10}(\mathrm{OH})_{2}$.

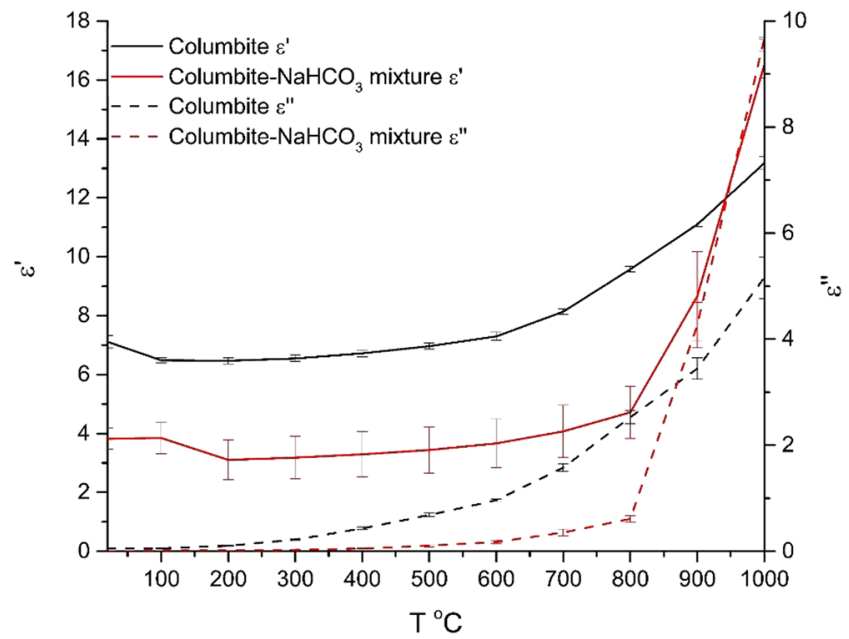

Figure 2. Comparison of the dielectric properties (average of 5 repetitions) of the columbite concentrate and its mixture with sodium bicarbonate at the industrial microwave frequency of $2470 \mathrm{MHz}$.

\section{Results and Discussion}

From Fig. 2, it is evident that the conversion of electromagnetic energy into heat (represented by the $\varepsilon^{\prime \prime}$ value) is dominated by the columbite concentrate, at least until $850 \mathrm{C}$. After this temperature the value of $\varepsilon^{\prime \prime}$ of the mixture grows exponentially until it reaches a value 1.6 times higher than the corresponding value for the columbite concentrate at $1000^{\circ} \mathrm{C}$ as a consequence of the products formed after roasting reaction. In a supplementary micro-wave heating superimposed onto a thermogravimetric plot in Fig. 3, three main regions labelled from A to $\mathrm{C}$ can be identified according to the variations in the dielectric parameter values.

In Region $\mathrm{A}$, the sample experienced a weight loss of roughly $17 \%$. This decrease can be explained by the loss of moisture from the sample and the melting of $\mathrm{NaHCO}_{3}$ with simultaneous decomposition to $\mathrm{Na}_{2} \mathrm{CO}_{3}$, carbon dioxide and steam in the range between $50^{\circ}$ and $270^{\circ} \mathrm{C}^{23}$. Additionally, the value of $\varepsilon^{\prime}$ decreases to about $19 \%$ of its starting value from $100^{\circ}$ to $200^{\circ} \mathrm{C}$. The conversion of $\mathrm{NaHCO}_{3}$ into $\mathrm{Na}_{2} \mathrm{CO}_{3}$ involves the breaking of the O-H dipole which mostly explains such a decrease in $\varepsilon^{\prime}$. The values of the loss parameter $\varepsilon^{\prime \prime}$ remain essentially constant up to $200^{\circ} \mathrm{C}$ and then slightly increase from $200^{\circ}$ to $300^{\circ} \mathrm{C}$. The increasing trend of the electrical conductivity of the $\mathrm{Na}_{2} \mathrm{CO}_{3}$ is probably the cause of the growing trend in $\varepsilon^{\prime \prime}$ after $200^{\circ} \mathrm{C}^{24,25}$. Other transformations observed within this temperature range include the incorporation of iron into the muscovite structure by forming a new mica phase, known as celadonite. This transformation is expected to occur due to the diffusion of iron ions from the columbite matrix to the muscovite inclusions ${ }^{26}$ (see Figures S2 and S3 and Table S3 in supplementary information). Both effects, the ionic mobility due to the liquid phase formation and the migration of the iron, contribute to increase the value of the dielectric loss from $200^{\circ}$ to $300^{\circ} \mathrm{C}$. 


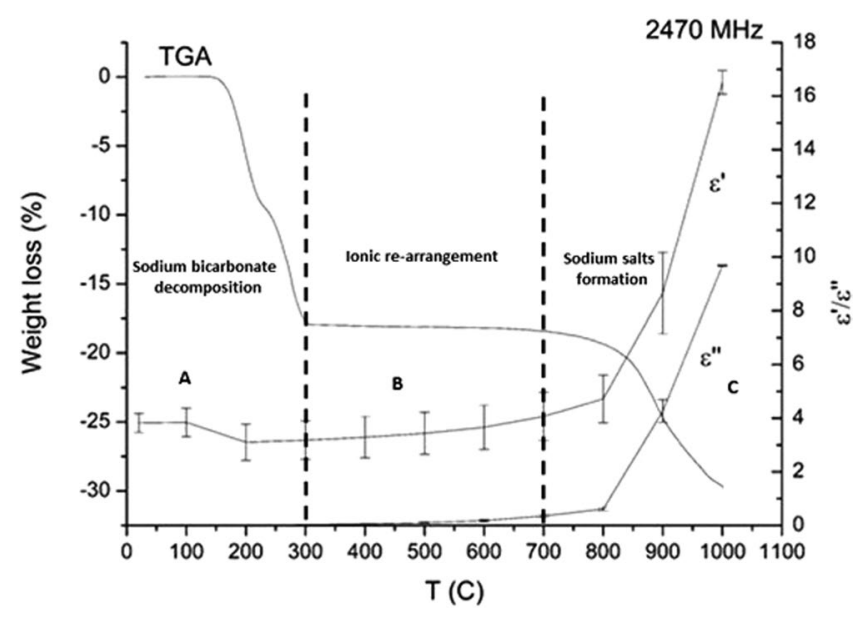

Figure 3. A correlation between the TGA weight loss and the dielectric properties $\varepsilon^{\prime}$ and $\varepsilon^{\prime \prime}$ with the temperature at the industrial microwave frequency of $2470 \mathrm{MHz}$.
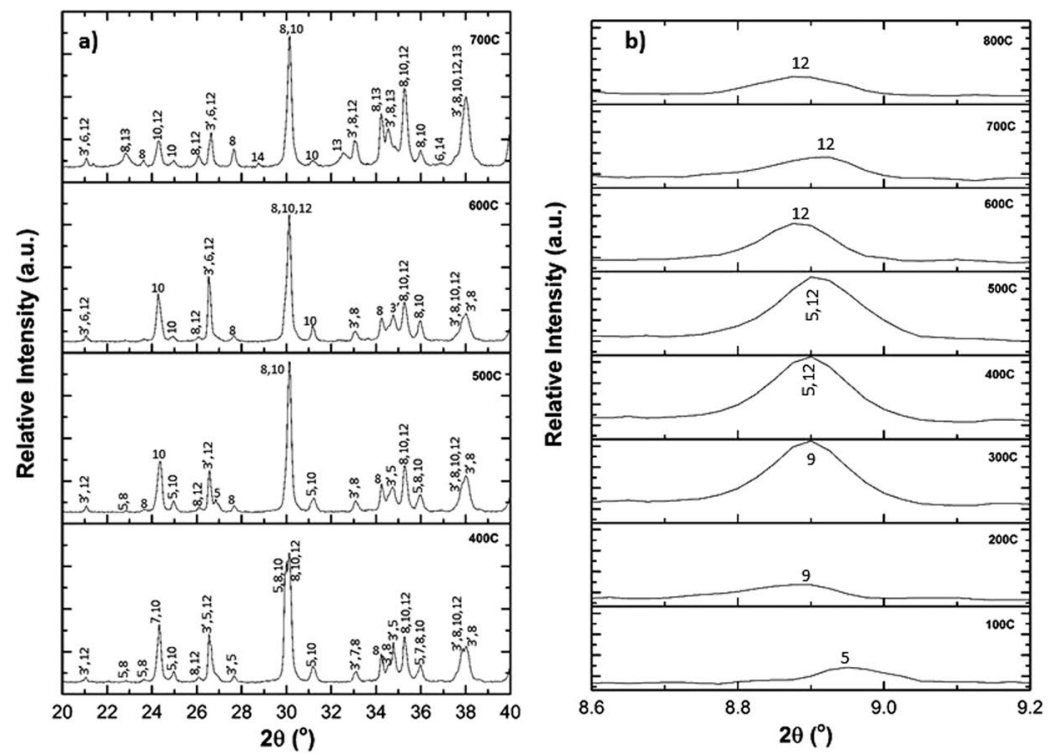

3'. $\mathrm{FeNb}_{0.2} \mathrm{Ta}_{1.8} \mathrm{O}_{6}$

5. $\mathrm{KAl}_{2}(\mathrm{Si}, \mathrm{Al})_{4} \mathrm{O}_{10}(\mathrm{OH})_{2}$

6. $\mathrm{SiO}_{2}$

7. $\mathrm{Fe}_{1.84} \mathrm{Al}_{0.16} \mathrm{O}_{3}$

8. $\mathrm{Na}_{2} \mathrm{CO}_{3}$

9. $\mathrm{K}(\mathrm{Fe}, \mathrm{Al})_{2}(\mathrm{Si}, \mathrm{Al})_{4} \mathrm{O}_{10}(\mathrm{OH})_{2}$ 10. $(\mathrm{Fe}, \mathrm{Mn})(\mathrm{Nb}, \mathrm{Ta})_{2} \mathrm{O}_{6}$ 12. $\mathrm{KFe}_{2.6} \mathrm{Al}_{1.8} \mathrm{Si}_{2.6} \mathrm{O}_{10}(\mathrm{OH})_{2}$

13. $\mathrm{NaNbO}_{3}$

14. $\mathrm{KAlSiO}_{4}$

Figure 4. A comparison of XRPD patterns of samples roasted from 400 to $700^{\circ} \mathrm{C}$. (a) $2 \Theta$; from 20 to $40^{\circ}$ and (b) $2 \Theta$; from 8.6 to $9.2^{\circ}$. The diffraction data compares well with ICDD refs.01-074 $\mathrm{FeNb}_{0.2} \mathrm{Ta}_{1.8} \mathrm{O}_{6}, 00-058$ $2034 \mathrm{KAl}_{2}(\mathrm{Si}, \mathrm{Al})_{4} \mathrm{O}_{10}(\mathrm{OH})_{2}, 01-085-0865 \mathrm{SiO}_{2}, 04-005-8669 \mathrm{Fe}_{1.84} \mathrm{Al}_{0.16} \mathrm{O}_{3}, 01-075-6816 \mathrm{Na}_{2} \mathrm{CO}_{3}, 00-033-0659$ $(\mathrm{Fe}, \mathrm{Mn})(\mathrm{Nb}, \mathrm{Ta})_{2} \mathrm{O}_{6}, 04-017-1456 \mathrm{KFe}_{2.6} \mathrm{Al}_{1.8} \mathrm{Si}_{2.6} \mathrm{O}_{10}(\mathrm{OH})_{2}, 04-012-8147 \mathrm{NaNbO}_{3}$ and 04-012-8404 $\mathrm{KAlSiO}_{4}$. In Fig. $4 \mathrm{~b}$ the changes in the diffraction intensity due to $\mathrm{Fe}^{3+}$ ion exchange between the original muscovite mineral $\left(\mathrm{KAl}_{2}(\mathrm{Si}, \mathrm{Al})_{4} \mathrm{O}_{10}(\mathrm{OH})_{2}\right)$ and the celadonite phase $\left(\mathrm{K}(\mathrm{Fe}, \mathrm{Al})_{2}(\mathrm{Si}, \mathrm{Al})_{4} \mathrm{O}_{10}(\mathrm{OH})_{2}\right)$ are compared by examining the intensities of phases.

A slight monotonic increase in both the $\varepsilon^{\prime}$ and $\varepsilon^{\prime \prime}$ values recorded in Region B might be attributed to the process leading to the formation of $\mathrm{NaNbO}_{3}$ at $700{ }^{\circ} \mathrm{C}^{17}$, and the consequent release of $\mathrm{Fe}_{2} \mathrm{O}_{3}$, according to reactions (2)-(4), as verified in Fig. 4a.

$$
\begin{gathered}
\mathrm{KFe}_{3}\left(\mathrm{AlSi}_{3} \mathrm{O}_{10}\right)(\mathrm{OH})_{2}+3 / 4 \mathrm{O}_{2(\mathrm{~g})} \rightarrow \mathrm{KAlSiO}_{4}+3 / 2 \mathrm{Fe}_{2} \mathrm{O}_{3}+\mathrm{H}_{2} \mathrm{O}_{(\mathrm{g})}+2 \mathrm{SiO}_{2} \\
\mathrm{KFe}_{3}\left(\mathrm{AlSi}_{3} \mathrm{O}_{10}\right)(\mathrm{OH})_{2}+\mathrm{Al}_{2} \mathrm{SiO}_{5}+3 / 4 \mathrm{O}_{2(\mathrm{~g})} \rightarrow \mathrm{KAl}_{2}\left(\mathrm{AlSi}_{3} \mathrm{O}_{10}\right)(\mathrm{OH})_{2}+1 / 2 \mathrm{Fe}_{2} \mathrm{O}_{3}+\mathrm{SiO}_{2} \\
(\mathrm{Fe}, \mathrm{Mn})(\mathrm{Nb}, \mathrm{Ta})_{2} \mathrm{O}_{6}+\mathrm{NaHCO}_{3} \rightarrow(\mathrm{Fe}, \mathrm{Mn}) \mathrm{Ta}_{2} \mathrm{O}_{6}+\mathrm{NaNbO}_{3}+\mathrm{CO}_{2}(\mathrm{~g})+\mathrm{H}_{2} \mathrm{O}_{(g)}
\end{gathered}
$$

Iron $\left(\mathrm{Fe}^{3+}\right)$, is incorporated into the muscovite structure $\left(\mathrm{KAl}_{2}(\mathrm{Si}, \mathrm{Al})_{4} \mathrm{O}_{10}(\mathrm{OH})_{2}\right)$ by forming a new family of mineral, known as celadonite $\left(\mathrm{K}(\mathrm{Fe}, \mathrm{Al})_{2}(\mathrm{Si}, \mathrm{Al})_{4} \mathrm{O}_{10}(\mathrm{OH})_{2}\right)$ until $300^{\circ} \mathrm{C}$, which begins to segregate above $400^{\circ} \mathrm{C}$ according to reactions (2) and (3). The analysis of the XRPD in the $2 \Theta$ range between 8.7 and $8.9^{\circ}$ in Fig. $4 \mathrm{~b}$ shows 


\begin{tabular}{|l|l|l|l|}
\hline $\begin{array}{l}\text { Temperature } \\
\left({ }^{\circ} \mathbf{C}\right)\end{array}$ & $\mathbf{2 \theta}\left(^{\circ}\right)$ & $\begin{array}{l}\text { Relative } \\
\text { Intensity (\%) }\end{array}$ & Phases \\
\hline 100 & 8.9601 & 2.96 & $\mathrm{KAl}_{2}(\mathrm{Si}, \mathrm{Al})_{4} \mathrm{O}_{10}(\mathrm{OH})_{2}$ \\
\hline 200 & 8.8855 & 3.80 & $\mathrm{~K}(\mathrm{Fe}, \mathrm{Al})_{2}(\mathrm{Si}, \mathrm{Al})_{4} \mathrm{O}_{10}(\mathrm{OH})_{2}$ \\
\hline 300 & 8.9334 & 19.65 & $\mathrm{~K}\left(\mathrm{Fe}, \mathrm{Al}_{2}\left(\mathrm{Si}_{2} \mathrm{Al}\right)_{4} \mathrm{O}_{10}(\mathrm{OH})_{2}\right.$ \\
\hline 400 & 8.8988 & 17.24 & $\mathrm{KAl}_{2}\left(\mathrm{Si}_{2}, \mathrm{Al}_{4} \mathrm{O}_{10}(\mathrm{OH})_{2} / \mathrm{KFe}_{2.6} \mathrm{Al}_{1.8} \mathrm{Si}_{2.6} \mathrm{O}_{10}(\mathrm{OH})_{2}\right.$ \\
\hline 500 & 8.9099 & 14.13 & $\mathrm{KAl}_{2}\left(\mathrm{Si}_{1}, \mathrm{Al}_{4}\right)_{4} \mathrm{O}_{10}(\mathrm{OH})_{2} / \mathrm{KFe}_{2.6} \mathrm{Al}_{1.8} \mathrm{Si}_{2.6} \mathrm{O}_{10}(\mathrm{OH})_{2}$ \\
\hline 600 & 8.8845 & 10.37 & $\mathrm{KFe}_{2.6} \mathrm{Al}_{1.8} \mathrm{Si}_{2.6} \mathrm{O}_{10}(\mathrm{OH})_{2}$ \\
\hline 700 & 8.9129 & 8.46 & $\mathrm{KFe}_{2.6} \mathrm{Al}_{1.8} \mathrm{Si}_{2.6} \mathrm{O}_{10}(\mathrm{OH})_{2}$ \\
\hline 800 & 8.8915 & 6.43 & $\mathrm{KFe}_{2.6} \mathrm{Al}_{1.8} \mathrm{Si}_{2.6} \mathrm{O}_{10}(\mathrm{OH})_{2}$ \\
\hline
\end{tabular}

Table 1. Comparison of the relative intensity and $2 \theta$ values for the peak located between 8.7 and $8.9^{\circ}$ at different temperatures. ICDD ref. values $\mathrm{KAl}_{2}(\mathrm{Si}, \mathrm{Al})_{4} \mathrm{O}_{10}(\mathrm{OH})_{2}=\left(8.889^{\circ}, 58 \%\right), \mathrm{K}(\mathrm{Fe}, \mathrm{Al})_{2}(\mathrm{Si}, \mathrm{Al})_{4} \mathrm{O}_{10}(\mathrm{OH})_{2}=\left(8.748^{\circ}\right.$, $100 \%)$ and $\mathrm{KFe}_{2.6} \mathrm{Al}_{1.8} \mathrm{Si}_{2.6} \mathrm{O}_{10}(\mathrm{OH})_{2}=\left(8.722^{\circ}, 100 \%\right)$.

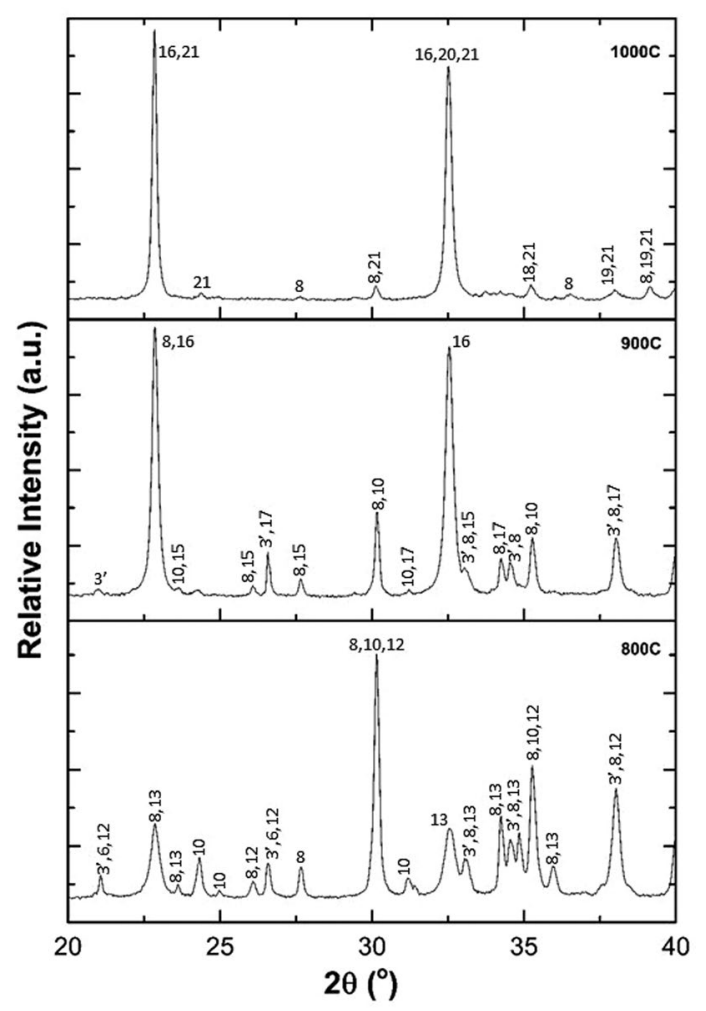

$$
\begin{aligned}
& \text { 3'. } \mathrm{FeNb}_{0.2} \mathrm{Ta}_{1.8} \mathrm{O}_{6} \\
& \text { 6. } \mathrm{SiO}_{2} \\
& \text { 8. } \mathrm{Na}_{2} \mathrm{CO}_{3} \\
& \text { 10. }(\mathrm{Fe}, \mathrm{Mn})(\mathrm{Nb}, \mathrm{Ta})_{2} \mathrm{O}_{6} \\
& \text { 12. } \mathrm{KFe}_{2.6} \mathrm{Al}_{1.8} \mathrm{Si}_{2.6} \mathrm{O}_{10}(\mathrm{OH})_{2} \\
& \text { 13. } \mathrm{NaNbO}_{3} \\
& \text { 15. } \mathrm{NaAlSi}_{2} \mathrm{O}_{6} \\
& \text { 16. } \mathrm{NaTa}_{0.6} \mathrm{Nb}_{0.4} \mathrm{O}_{3} \\
& \text { 17. } \mathrm{KAISi}_{2} \mathrm{O}_{6} \\
& \text { 18. } \mathrm{Na}_{3} \mathrm{NbO}_{4} \\
& \text { 19. } \mathrm{NaMnO}_{2} \\
& \text { 20. } \mathrm{Na}_{0.7} \mathrm{Fe}_{0.7} \mathrm{Mn}_{0.3} \mathrm{O}_{2} \\
& \text { 21. } \mathrm{Na}_{12} \mathrm{Al}_{12} \mathrm{Si}_{12} \mathrm{O}_{48}
\end{aligned}
$$

Figure 5. A comparison of the XRPD patterns of samples roasted from 800 to $1000^{\circ} \mathrm{C}$. Here the $2 \Theta$; from 20 to $40^{\circ}$ range has been selected, in which the diffraction data compares well with ICDD refs.01-074 $\mathrm{FeNb}_{0.2} \mathrm{Ta}_{1.8} \mathrm{O}_{6}, 01-085-1780 \mathrm{SiO}_{2}, 04-011-4108 \mathrm{Na}_{2} \mathrm{CO}_{3}, 00-033-0659$ (Fe, Mn)(Nb, Ta $)_{2} \mathrm{O}_{6}, 04-017-1456$ $\mathrm{KFe}_{2.6} \mathrm{Al}_{1.8} \mathrm{Si}_{2.6} \mathrm{O}_{10}(\mathrm{OH})_{2}, 04-012-8147 \mathrm{NaNbO}_{3}, 01-082-9616 \mathrm{NaAlSi}_{2} \mathrm{O}_{6}, 04-006-6542 \mathrm{NaTa}_{0.6} \mathrm{Nb}_{0.4} \mathrm{O}_{3}, 00-031-$ $0967 \mathrm{KAlSi}_{2} \mathrm{O}_{6}, 00-022-6542 \mathrm{Na}_{3} \mathrm{NbO}_{4}, 04-010-1809 \mathrm{NaMnO}_{2}, 00-053-0349 \mathrm{Na}_{0.7} \mathrm{Fe}_{0.7} \mathrm{Mn}_{0.3} \mathrm{O}_{2}$ and 01-071-0370 $\mathrm{Na}_{12} \mathrm{Al}_{12} \mathrm{Si}_{12} \mathrm{O}_{48}$.

that the incorporation of iron in the structure results in a decrease of the $2 \theta$ values and an increase of the relative intensity of the peaks located within the range (see also Table 1$)^{27}$. An apparent discrepancy in the measured $2 \theta$ values might be attributed to the overlap of the phases 5, 9 and 12, as can be deduced from the peak broadening in Fig. 4b. The SEM/EDX analysis are included in Figure S4 and Table S4 of the supplementary information. In the temperature range of region $\mathrm{C}\left(800^{\circ}-900^{\circ} \mathrm{C}\right)$, an exponential increase in the values of the dielectric properties was observed. This increase is attributed to the formation of niobium/tantalum sodium complexes observed in the XRPD pattern shown in Fig. 5, and in the supplementary SEM/EDX analysis included in Figure S5 and Table S5 of the supplementary information. The oxide $\mathrm{NaTa}_{0.6} \mathrm{Nb}_{0.4} \mathrm{O}_{3}$ has a perovskite structure with the general formula $\mathrm{A}^{+} \mathrm{B}^{5+} \mathrm{O}_{3}$, in which the $\mathrm{B}$ positions are occupied by the highly charged $\mathrm{Nb}^{5+}(0.78 \AA)$ and $\mathrm{Ta}^{5+}(0.78 \AA)$. Such a crystalline structure induces a spontaneous alignment of dipoles due to off-centre displacement of the B-site cations within their octahedral co-ordination, by imparting ferroelectric properties, which may be related with the exponential increase of the dielectric properties ${ }^{28}$. 


\begin{tabular}{|l|l|l|l|}
\hline Temperature $\left({ }^{\circ} \mathbf{C}\right)$ & $\varepsilon^{\prime}$ & $\varepsilon^{\prime \prime}$ & $\delta(\mathbf{m})$ \\
\hline 20 & 3.82 & 0.008 & 4.723 \\
\hline 100 & 3.84 & 0.010 & 3.788 \\
\hline 200 & 3.10 & 0.011 & 3.094 \\
\hline 300 & 3.18 & 0.024 & 1.436 \\
\hline 400 & 3.29 & 0.052 & 0.674 \\
\hline 500 & 3.44 & 0.104 & 0.345 \\
\hline 600 & 3.66 & 0.177 & 0.209 \\
\hline 700 & 4.07 & 0.355 & 0.110 \\
\hline 800 & 4.72 & 0.612 & 0.069 \\
\hline 900 & 8.66 & 4.263 & 0.014 \\
\hline 1000 & 16.52 & 9.678 & 0.008 \\
\hline
\end{tabular}

Table 2. Calculation of the penetration depth $(\mathrm{m})$ for the roasting of the mixture columbite-sodium bicarbonate at $2470 \mathrm{MHz}$.

The interacting microwave field distributes within the material under test, as apparent from the measured dielectric properties. The interacting field then is blocked by the resistivity (losses) encountered during its propagation within the sample. The depth at which the microwave power field decays to a factor 1/e (approx. $37 \%$ ) of the value at the surface is conventionally assumed as the 'penetration depth' of the material and it is calculated by the following equation ${ }^{29}$ :

$$
D_{p}=\frac{\lambda_{0}}{2 \pi \sqrt{2 \varepsilon^{\prime}}} \frac{1}{\sqrt{\left[\left\{1+\left(\frac{\varepsilon^{\prime \prime}}{\varepsilon^{\prime}}\right)^{2}\right\}^{0.5}-1\right]}}
$$

where $D_{p}$ is the penetration depth in meters, $\varepsilon^{\prime}$ and $\varepsilon^{\prime \prime}$ are the real and imaginary part of the permittivity of the medium, respectively, $\lambda_{0}$ is the wavelength related to the operating frequency in free space. In the case of columbite-sodium bicarbonate mixture, the calculation of the penetration depth was performed at the different stages and temperatures of reaction and the results are reported in Table 2.

The differences in the penetration depth of the microwave field are important and will require careful consideration within the future development of this process in terms of energy uniformity applied to a batch or continuous process, especially at temperatures above $800^{\circ} \mathrm{C}$, for example the penetration depth of $\sim 1.5 \mathrm{~cm}$ into the material at $900^{\circ} \mathrm{C}$. However, depending on the change in dielectric properties with frequency, it is expected that penetration depth will increase with decreasing frequency (for example at room temperature $\delta=10.814 \mathrm{~m}$ at $910 \mathrm{MHz}$ while it is $\delta=4.723 \mathrm{~m}$ at $2470 \mathrm{MHz}$ ). Careful consideration of cavity/applicator geometry and material feed profile can address these limitations ${ }^{29}$.

\section{Conclusions}

A correlation between the changes in the dielectric properties and the physico-chemical transformations in mineral phases occurring during the roasting of columbite with sodium bicarbonate has been investigated and analysed for the first time for engineering a microwave heating methodology for selective separation of tantalum and niobium oxide constituents as alkali complexes. The results show that there are three different regions which can be characterised by comparing the changes in the dielectric and thermogravimetric characterization, as shown in Fig. 3, in which the region $\mathrm{A}$ is dominated by the decomposition of sodium bicarbonate with a small decrease in the dielectric constant. In region $\mathrm{B}$ an ionic rearrangement of the columbite matrix occurs which is driven by the iron diffusion into the muscovite inclusions by forming celadonite type minerals. Further segregation of $\mathrm{Fe}_{2} \mathrm{O}_{3}$ from celadonite above $400^{\circ} \mathrm{C}$ and the formation of $\mathrm{NaNbO}_{3}$ at $700^{\circ} \mathrm{C}$ are the consequences of the slightly increase in the dielectrics observed in this region. The exponential increase in the dielectric properties observed in region $\mathrm{C}$ is attributed to the formation of sodium complexes especially to $\mathrm{NaTa}_{0.6} \mathrm{Nb}_{0.4} \mathrm{O}_{3}$.

The analysis of the penetration depth of the microwave heating shows that this parameter decreases at higher temperatures indicating the necessity for a careful selection of the reactor geometry in future, for the design of a process based on dielectric heating.

\section{References}

1. Niobium: Market Outlook to 2017 12th Edition, Roskill Information Services Ltd., London, 2013.

2. Tantalum: Global Industry, Markets and Outlook to 2020, Roskill Information Services Ltd., London, 2016.

3. Zhu, Z. \& Cheng, C. Y. Solvent extraction technology for the separation and purification of niobium and tantalum: A review. Hydrometallurgy 107, 1-12 (2011)

4. Rodriguez, M. H., Rosales, G. D., Pinna, E. G. \& Suarez, D. S. Extraction of niobium and tantalum from ferrocolumbite by hydrofluoric acid pressure leaching. Hydrometallurgy 156, 17-20 (2015).

5. Ayanda, O. S. \& Adekola, F. A. A review of niobium-tantalum separation in hydrometallurgy. JMMCE 10, 245-256 (2011).

6. Polyakov, E. G. \& Polyakova, L. P. Current trends in the production of tantalum and niobium. Metallurgist 47, 33-41 (2003).

7. Brocchi, E. A. \& Moura, F. J. Chlorination methods applied to recover refractory metals from tin slags. Miner. Eng. 21, 150-156 (2008).

8. Gonzalez, J. et al. Chlorination of niobium and tantalum ore. Thermochim. Acta 311, 61-69 (1998). 
9. Kanari, N. et al. An overview study of chlorination reactions applied to the primary extraction and recycling of metals and to the synthesis of new reagents. Thermochim. Acta 495, 42-50 (2009).

10. Rodriguez, M. H., Rosales, G. D., Pinna, E. G. \& Suarez, D. S. Effect of $\mathrm{Na}^{+}$ion on the dissolution of ferrocolumbite in autoclave. Hydrometallurgy 159, 60-64 (2016).

11. Mudzanapabwe, N. T., Chinyamakobvu, O. S. \& Simbi, D. J. In situ carbothermic reduction of a ferro-columbite concéntrate in the recovery of $\mathrm{Nb}$ and $\mathrm{Ta}$ as metal matrix composite from tin smelting slag waste dump. Mater. Des. 25, 297-302 (2004).

12. Kabangu, M. J. \& Crouse, P. L. Separation of niobium and tantalum from Mozambican tantalite by ammonium bifluoride digestion and octanol solvent extraction. Hydrometallurgy 129-130, 151-155 (2012).

13. Panias, D. Consequences of environmental issues on sustainability of metal industries inEurope: The case study of Bor. Metalurgija 12, 239-250 (2006).

14. Parirenyatwa, S., Escudero-Castejon, L., Sanchez-Segado, S., Hara, Y. \& Jha, A. Comparative study of alkali roasting and leaching of chromite ores and titaniferous minerals. Hydrometallurgy 165, 213-226 (2016).

15. Sanchez-Segado, S., Lahiri, A. \& Jha, A. Alkali roasting of Bomar ilmenite: rare earths recovery and physico-chemical changes. Open Chem. 13, 270-278 (2016).

16. Sanchez-Segado, S., Makanyire, T., Escudero-Castejon, L., Hara, Y. \& Jha, A. Reclamation of reactive metal oxides from complex minerals using alkali roasting and leaching-an improved approach to process engineering. Green Chem. 17, 2059-2080 (2015).

17. Sanchez-Segado, S., Ruzaidi, A. F., Zhang, Y. \& Jha, A. Characterization of Physico-Chemical Changes during the Alkali Roasting of Niobium and Tantalum Oxides in Drying, Roasting, and Calcining of Minerals (ed. Battle T. P. et al.) 51-58 (Springer, 2015).

18. Kingman, S. W. Recent developments in microwave processing of minerals. Int. Mater. Rev. 51, 1-12 (2006).

19. Batchelor, A. R., Jones, D. A., Plint, S. \& Kingman, S. W. Increasing the grind size for effective liberation and flotation of a porphyry copper ore by microwave treatment. Miner. Eng. 94, 61-75 (2016)

20. Stuerga, D. Microwave-Material Interactions and Dielectric Properties, Key Ingredients for Mastery of Chemical Microwave Processes in Microwaves in Organic Synthesis 1-61 (ed. A. Loupy, Wiley-VCH Verlag GmbH\&Co, 2008).

21. Monti, T. et al. High-resolution dielectric characterization of minerals: A step towards understanding the basic interactions between microwaves and rocks. Int. J. Miner. Process 151, 8-21 (2016).

22. Slocombe, D., Porch, A., Bustarret, E. \& Williams, O. A. Microwave properties of nano-diamond particles. Appl. Phys. Lett. 102, $244102(2013)$.

23. Hartman, M., Svoboda, K., Pohorely, M. \& Syc, M. Thermal decomposition of sodium hydrogen carbonate and textural features of its calcines. Ind. Eng. Chem. Res. 52, 10619-10626 (2013).

24. Janz, G. J. \& Lornz, M. R. Molten carbonates electrolytes: Physical properties, structure, and mechanism of electrical conductance. J. Electrochem. Soc. 108, 1052-1058 (1961).

25. Näfe, H. Conductivity of alkali carbonates, carbonate-based composite electrolytes and IT-SOFC. ECS J. Sol. St. Sci. Tech. 3, N7-N14 (2014).

26. Melka, K. A scheme for the classification of micaceous minerals. Acta Geodyn. Geomater. 6, 69-75 (2009).

27. Crowley, M. S. \& Roy, R. Cristallyne solubility in the muscovite and phlogopite groups. Am. Mineral. 49, 348-362 (1964).

28. Chen, X. M., Lu, Y. T., Jin, D. Z. \& Liu, X. Q. Dielectric and ferroelectric characterization of $\mathrm{Na}(\mathrm{Ta}, \mathrm{Nb}) \mathrm{O}_{3}$ solid solution ceramics. J. Electroceram. 15, 21-26 (2005).

29. Roger, M. Engineers' handbook of industrial microwave heating. No. 25. IET, 1998.

\section{Acknowledgements}

The authors acknowledge the financial support from the European Union's Individual International Marie Curie Fellowship grant number 331385 for Dr. Sanchez-Segado, the NERC SoS RARE grant (NE/M01147X/1) and the NERC's Catalyst Grant reference NE/L002280/1.

\section{Author Contributions}

S. Sanchez-Segado, T. Monti, J. Katrib, S. Kingman, C. Dodds and A. Jha conceived and designed the study. S. Sanchez-Segado, T. Monti and J. Katrib performed the experiments and processed the data. S Kingman, C. Dodds and $\mathrm{A}$. Jha contributed to the discussion of the results and coordination of the work.

\section{Additional Information}

Supplementary information accompanies this paper at https://doi.org/10.1038/s41598-017-18272-3.

Competing Interests: The authors declare that they have no competing interests.

Publisher's note: Springer Nature remains neutral with regard to jurisdictional claims in published maps and institutional affiliations.

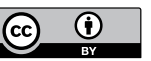

Open Access This article is licensed under a Creative Commons Attribution 4.0 International License, which permits use, sharing, adaptation, distribution and reproduction in any medium or format, as long as you give appropriate credit to the original author(s) and the source, provide a link to the Creative Commons license, and indicate if changes were made. The images or other third party material in this article are included in the article's Creative Commons license, unless indicated otherwise in a credit line to the material. If material is not included in the article's Creative Commons license and your intended use is not permitted by statutory regulation or exceeds the permitted use, you will need to obtain permission directly from the copyright holder. To view a copy of this license, visit http://creativecommons.org/licenses/by/4.0/.

(C) The Author(s) 2017 